\title{
La corporeidad como apertura del hombre al mundo
}

\author{
Miguel Ángel Villamil-Pineda*
}

Resumen: Nuestra condición de sujetos corpóreos nos muestra el mundo no como un hábitat natural específico, sino como un universo de posibilidades de sentido, al cual podemos acceder desde infinitas orientaciones. El ser humano no está determinado a priori por la naturaleza, como los animales, sino que él mismo constituye su propio mundo a partir de sus expectativas y necesidades. Vista desde el mundo animal, la corporeidad humana no es especializada; comparado con el animal, el hombre aparece como el hijo más huérfano de la naturaleza. Sin embargo, vista desde el mundo cultural, la corporeidad humana se manifiesta como una realidad sui generis, que le permite al hombre trascender los límites impuestos por la naturaleza y responder a ellos de forma creativa. El objetivo de este trabajo consiste en mostrar la corporeidad humana como fundamento y condición de posibilidad de cualquier tipo de cultura.

Palabras clave: Corporeidad, subjetividad, especialización cultural, hábitat, mundo, cultura.

\begin{abstract}
Our condition as beings with bodily substance shows us the world not as a specific natural habitat, but as a universe of possibilities of meaning that can be accessed or approached from countless directions. The human being is not determined a priori by nature, as are animals, but constructs his own world based on his expectations and needs. Seen from the perspective of the animal world, human corporality is not specialized. Compared to animals, man appears as nature's most orphaned son. However, viewed from the cultural world, human corporality is manifest as a sui generis reality, one that allows man to transcend the limits imposed by nature and to respond to them in a creative way. The purpose of this work is to show human corporality as the basis and condition for any type of culture.
\end{abstract}

Keywords: Corporality, subjectivity, cultural specialization, habitat, world, culture.

Résumé: Notre condition de sujets corporéens nous montre le monde non pas comme un habitat naturel spécifique, mais plutôt comme un univers de sens possibles auquel nous pouvons accéder depuis des horizons infinis. L'être humain n'est pas déterminé a priori par la nature, comme les animaux ; il constitue en lui-même son propre monde en partant de ses attentes et de ses besoins. Vue depuis le monde animal, la corporéité humaine n'est pas spécialisée ; comparé à l'animal, l'homme apparaît comme l'enfant le plus orphelin de la nature. Toutefois, considérée depuis le monde culturel, la corporéité humaine se manifeste comme une réalité sui generis qui permet à l'homme de transcender les limites imposées par la nature et d'y répondre de manière créative. La finalité de cette étude consiste à montrer la corporéité humaine comme base et comme condition de possibilité de tout type de culture.

Mots-clés: Corporéité, subjectivité, spécialisation culturelle, habitat, monde, culture.

* Magíster en Filosofía. Director de Programa de la Licenciatura en Filosofía de la Universidad de San Buenaventura, sede Bogotá, Colombia. (MVillamil@usbbog.edu.co).

Recibido: 2010 - 04 - 30

Aprobado: 2010 - 05 - 28 


\section{Introducción}

El hecho primario de la fenomenología existencial es la existencia concebida como la apertura del sujeto a todo lo que no sea sujeto propio ${ }^{1}$. Dicha concepción entraña ya la corporeidad como nota esencial, sin la cual sería imposible la comunicación del sujeto con los demás seres del mundo. De esta manera, nos liberamos de la esclavitud del objeto $\mathrm{y}$, a la vez, de las posibles arbitrariedades del sujeto; ambas tesis sustentadas por los sistemas filosóficos clásicos: el empirismo y el racionalismo.

El cuerpo propio nos muestra al hombre como el entramado de relaciones que ve a la subjetividad no como algo dado o determinado a priori por la naturaleza, o por cualquier otro ser, sino como un ser inacabado, una construcción, una tarea a realizar en co-relación con los demás seres del mundo². Así, la idea de subjetividad ejerce una fuerza decisiva en la autorealización de nuestra existencia propia, ya que a partir de ella podemos sobrevivir, regir y modelar nuestras experiencias y vivencias: "el hombre es un ser que se pregunta y se interpreta a sí mismo porque sabe que necesita una imagen rectora que le ayude a construirse y constituirse" 3 .

En consecuencia, el hombre, en cuanto ser de relaciones, es hacedor $\mathrm{y}$, al mismo tiempo, hechura de su propio ser: ser hombre es hacerse y dejarse hacer hombre. Por tanto, el hecho primario de la filosofía nos lleva a preguntarnos, en un primer momento, por el modo como el

1 Cfr. A. Dondeyne, Fe cristiana y pensamiento contemporáneo, traducción de J. Martín Velasco, Madrid, Cristiandad, 1963, pp. 68-69.

2 Cfr. A. Gehlen, El hombre: su naturaleza y su lugar en el mundo, traducción de C. Vevia, Salamanca, Sígueme, 1987, p. 18.

3 M. Landmann, Antropología filosófica: autointerpretación del hombre en la historia y en el presente,, traducción de C. Moreno, México, Uteha, 1961, pp. 9-10. sujeto-corpóreo vive y experimenta; $\mathrm{y}$, en un segundo momento, por el modo como el sujetocorpóreo piensa, racionaliza y crea, a partir de sus vivencias y experiencias, esquemas conceptuales, tales como la ciencia y la filosofía (no es azar que dichos esquemas sean históricamente tardíos). Por eso, antes de introducirnos en este tipo de racionalidad, debemos dirigir nuestra atención hacia la corporeidad-inteligente $e^{4}$, ya que ésta es el prerrequisito de aquélla. Ambos momentos nacen del sujeto-corpóreo y nos dan noticias del ser íntegro y total que incesantemente se está experimentando y re-creando.

La antropología dualista pasó por alto esta realidad y cometió el error de dividir tangencialmente la totalidad del hombre en dos partes irreconciliables: razón y physis. El problema es que la unidad integral humana, de la cual debe partir todo filosofar auténtico, ya no puede alcanzarse por la vía de la abstracción, es irrecuperable ${ }^{5}$. La descomposición del hombre en razón y physis, desencadena forzosamente en la concepción de un ser racional por una parte y un ser vivo por otra. Por eso, fue necesario construir dos grupos de ciencias diferentes: las humanas y las naturales. Los científicos pensaron ingenuamente que la sumatoria de los datos ofrecidos por sendos grupos de ciencias, daría como resultado la totalidad del hombre. Sin embargo, tal sueño nunca se hizo ni se hará realidad. El único resultado que se deriva por esta vía es el esparcimiento en átomos de la totalidad del hombre.

4 El niño recién nacido ya hace uso de su inteligencia, años más tarde hace uso de especial de la inteligencia que llamamos uso de razón (aquella en la cual puede hacer uso de la capacidad discursiva; es decir, de la capacidad de inferir y concluir). El niño desde sus comienzos es inteligente, pero no racional. No hay que reservar el vocablo hombre tan sólo a la racionalidad. La razón es un estadio de la evolución progresiva del hombre. Cfr. X. Zubiri, Siete ensayos de antropología filosófica, G. Martínez (ed.), Bogotá, USTA, 1982, pp. 40-42.

5 Cfr. M. Buber, Eclipse de Dios: estudios sobre las relaciones entre religión y filosofía, traducción de L. Fabricant ; introducción de R. M. Seltzer, México, FCE, 1970, p. 66. 
La antropología dualista, aún vigente en nuestros días, coloca su énfasis en la división de lo corporal y lo racional. Para ella siguen siendo relevantes las definiciones zoológicas o mecanicistas de las teorías clásicas: bípedo implume (Platón), animal racional (Aristóteles), máquina pensante (Descartes), animal enfermo (Nietzsche), animal económico (Marx)...

La antropología fenomenológica abandona dichos postulados, coloca el énfasis en la co-relación y concibe al hombre como la unidad cuya individualidad se funda a partir de la corporeidad. Por tal motivo, al hombre no lo podemos abordar separadamente como un ser vivo por una parte y como un ser racional por otra. Siempre debemos comprender ambos momentos como indisolubles: el hombre es un ser corpóreo tanto en la experiencia vivida como en la experiencia re-flexiva. La antropología filosófico-biológica y la medicina sico-somática, por ejemplo, son dos disciplinas que se enmarcan dentro de este campo de investigación ${ }^{6}$.

Lo anterior nos lleva a decir que la corporeidad humana es una realidad original $y$, por ende, esencialmente diferente a la de los demás seres vivos. Ella condiciona y posibilita todas las experiencias humanas, incluida la racionalidad lógico-analítica. Desarrollamos este tipo de destreza gracias a que nuestra corporeidad nos lo permite ${ }^{7}$. Los sentidos humanos no son como los sentidos animales, ellos no están determinados por la naturaleza, sino abiertos al mundo. En virtud de esta apertura sensorial, debemos y podemos crear cultura. La no determinación natural, no especialización, del cuerpo humano nos lanza a relacionarnos con el mundo, aprehenderlo y transformarlo en favor de nuestras intenciones. Veamos más detenidamente cómo nuestra arquitectura nos brinda esta oportunidad y cómo la constitución animal está negada desde un principio para tales fines.

6 Cfr. P. Chauchard, Compendio de biología humana las bases orgánicas de la conducta y del pensamiento; traducción de M. Testa; revisión de M. Balaguer, Buenos Aires, Universitaria, 1961, p. 360.

7 Cfr. Zubiri, Siete ensayos..., ob. cit., pp. 27-54.

\section{La no especialización natural del cuerpo humano}

Desde una actitud negativa tenemos que reconocer que la diferencia esencial entre el hombre y el animal, radica en que la constitución natural del hombre no es tan especializada como la del animal. Los órganos y sentidos animales son más perfectos y están estrictamente adecuados a las condiciones y exigencias peculiares de su vida. El animal posee una especie de ley natural que prescribe su comportamiento en cada situación:

comparado con el animal, el hombre aparece como el hijo más huérfano de la naturaleza: desnudo e inerme, débil y pobre, tímido y desarmado; y lo que acrecienta la suma de su desgracia: desprovisto de toda guía de la vida. El carácter natural de la raza humana consiste en fallas y carencias ${ }^{8}$.

El animal, en virtud de sus órganos e instintos especializados, está adecuado al medio y por ello necesita de condiciones de vida muy específicas para poder subsistir. Cada especie animal tiene sus funciones en su espacio vital (hábitat). Cuando sobreviene un cambio en dichas condiciones -como la alteración del clima, el agotamiento de una fuente de alimento, el surgimiento de nuevos enemigos...- la mayoría de especies animales no logran sobrevivir. Las que logran salvarse, tras un desgastador esfuerzo, deben adaptarse a las nuevas condiciones y estereotiparlas. La especialización, que en circunstancias normales se les muestra como un beneficio, en estos casos se convierte en fatalidad.

El hombre, desde un principio, carece de esta especialización. Antes bien, nosotros tenemos que desarrollar por aptitudes que nos compensen y transformen dicha carencia en oportunidades para la prolongación de nuestra vida. Los órganos humanos no están destinados parcialmente sólo a determinadas ejecuciones y, por tanto, están en plena desventaja con respecto a los órganos animales. Dentro de la

8 Landmann, Antropología..., ob. cit., p. 242. 
escala animal, el hombre es un ser necesitado que ocupa uno de los lugares más bajos:

al hombre le falta el revestimiento de pelo, los órganos de ataque, la formación corporal apropiada para la huída. Además es superado por la mayoría de animales en la agudeza de los sentidos. El hombre tiene una carencia mortalmente peligrosa para su vida. Dentro de las meras condiciones naturales, ya hace tiempo que se hubiera extinguido. Para prolongar su existencia, el hombre, desde un principio, debe ser capaz de experimentar, transformar y dominar la naturaleza9.

Pero la no especialización del hombre nos lleva a comprender que nosotros somos un proyecto absolutamente sui generis. La especialización debe faltarnos porque nosotros respiramos un contenido totalmente distinto. Más aún, la especialización sería un estorbo para nuestro plan estructural ${ }^{10}$.

La carencia del hombre es suplida por un principio de organización que sólo es connatural a su ser: la subjetividad ${ }^{11}$. La corporeidad humana respira subjetividad, lo cual nos da cierta independencia de la naturaleza y nos permite decidir sobre nuestras propias situaciones: "el hombre es el primer liberto de la creación, está organizado para la libertad. No es una máquina infalible en manos de la naturaleza. Él se convierte a sí mismo en meta y objeto de su trabajo" ${ }^{\prime 2}$.

El hombre, a diferencia del animal, no recibe para cada situación la norma preestablecida de comportamiento. Por eso: estamos más llenos de porvenir; podemos soportar las catástrofes con más fortaleza que todos los mamíferos superiores; no estamos sometidos a la tiranía del hábitat; podemos determinar las costumbres por nuestros propios medios; podemos decidir sobre la sexualidad sin estar atados al celo; nuestro género es el único que es capaz de

9 Gehlen, El hombre..., ob. cit., pp. 15-37.

10 Cfr. Zubiri, Siete ensayos..., ob. cit., pp. 27-54.

11 Cfr. Gehlen, El hombre..., ob. cit., p. 40.

12 Landmann, Antropología..., ob. cit., p. 252. extenderse sobre toda la tierra (el hombre habita tanto en el polo como en el desierto; en la tierra como en el mar...).

La no especialización significa para el hombre una apreciable ventaja debido a que nuestros órganos no están adecuados sólo a unos pocos trabajos, sino abiertos a una enorme diversidad de tareas. La corporeidad humana, al no estar gobernada por el instinto, sino a disposición de su propia organización, puede aspirar a crear y construir un mundo para ella que rebase las fronteras deterministas del hábitat, el mundo cultural. Si para el animal la naturaleza es su morada, para el hombre su morada es el mundo cultural. Por consiguiente, la falta de especialización es compensada por la multiplicidad de aptitudes y por la potencia de su propia iniciativa. Nuestra existencia puede hacerse más fácil gracias a nuestros inventos y estructuras sociales y, de esta manera, podemos incluso dominar al animal, aparentemente mejor equiparado para la lucha por la supervivencia ${ }^{13}$.

La subjetividad se nos muestra así como el co-relato necesario de la corporeidad humana, en virtud del cual hacemos frente a la carencia de especialización. Ahora, en términos positivos, debemos reconocer que la diferencia esencial entre el hombre y el animal, radica en que el hombre es el único ser que posee una corporeidad subjetivada. Con respecto a ésta, el animal es tan sólo un ser de carencias, y el hombre es el ser que ocupa el puesto más alto dentro de todos los seres.

El hombre, en cuanto corporeidad subjetivada, no percibe las cosas como dadas de una sola forma, sino que las percibe universalmente de modo que pueda aplicarlas a múltiples propósitos $^{14}$. Si bien es cierto que cada uno de nosotros procura obedecer a las conductas vitales estructuradas por la cultura propia, no obstante nuestro ser no está firmemente atado a ningún comportamiento preestablecido. De la misma manera como aprendemos podemos

13 Cfr. ibídem, pp. 209-210.

14 Cfr. M. Merleau-Ponty, Fenomenología de la percepción, traducción de J. Cabanes, Barcelona, Península, 1975, p. 219. 
des-aprender, cambiar o re-crear los estilos de conducta culturales:

el hombre no tiene ningún ambiente único naturalmente adecuado, en cada nuevo ambiente puede adquirir una conducta adecuada. Es por esta razón que el hombre puede vivir en cualquier lugar del mundo, ya que mediante un movimiento proyectado puede crear para sí su esfera cultural a partir de cualquier circunstancia existente ${ }^{15}$.

El esquema determinista de estímulo-respuesta es válido sólo dentro del reino animal. Aquí todas las respuestas están mediatizadas por el instinto. En el caso del hombre hablamos de una respuesta creadora, en virtud de la cual siempre podemos estructurar formas nuevas y superiores de cultura. Allí donde el animal responde instintivamente al hábitat, el hombre lo hace creativamente realizando mundos culturales. Es decir, el mundo natural es para el animal, lo que el mundo cultural es para el hombre. La influencia del hombre convierte al mundo natural en mundo cultural o humano ${ }^{16}$. Por tanto, para el hombre no existe ninguna posibilidad de vida en una naturaleza no cambiada, no humanizada. No hay ninguna humanidad sin fuego, armas, alimentos preparados ${ }^{17}$.

Pero el hombre, además de dar una respuesta creadora, además de ser hacedor de cultura, es también al mismo tiempo hechura cultural; inclusive el hombre sólo es creador de cultura en la medida en que sea creado por la cultura. Por eso, la intersubjetividad -ser-en-el-mundo-conotros- figura como nota esencial dentro de su plan estructural. Lo esencial del obrar humano es actuar a dúo, aún en el campo pre-lingüístico. La experiencia no es un proceso aislado, por cuanto que la estructura básica de todo lo humano es actuar sobre un tú ${ }^{18}$. El hombre se hace hombre sólo entre hombres, es decir, para hacer hombres debemos ser varios, para ser culturales

\footnotetext{
15 Ibídem., pp. 216-217.

16 Cfr. W. Lyupen, Fenomenología existencial, traducción de P. Martín, Buenos Aires, Carlos Lohlé, 1967, p. 35.

17 Cfr. Gehlen, El hombre..., ob. cit., p. 42

18 Cfr. ibídem, p. 194.
}

debemos ser comunitarios: "la armazón sicosomática que el hombre recibe desde su nacimiento constituye sólo una parte de su realidad total. No existiría la cultura sin el hombre que la realiza, pero éste tampoco sería nada sin ella"19.

Ya desde el principio, el mundo cultural ejerce una fuerza insustituible en el ritmo de desarrollo de la corporeidad humana. Los mamíferos de igual tamaño, por ejemplo, poseen una etapa de gestación más larga que la del hombre, ya que antes de salir al mundo deben madurar más sus órganos y defensas instintivas (no es gratuito que el cachorro adquiera su madurez y sus hábitos de defensa en un tiempo mucho más corto que el niño recién nacido). El animal al nacer sabe todo lo que puede saber. El hombre debe aprender todo. De aquí que llegue más expuesto al mundo y que su desarrollo sea más lento. El hombre, gracias a su sólida estructura social, pierde un año intrauterino pero a la par gana un año para su formación cultural ${ }^{20}$. El nacimiento prematuro del niño hace que él necesite ponerse muy pronto en contacto con sus congéneres sociales, y que este contacto se prolongue durante mucho más tiempo que en el animal. El niño desde un principio crece, madura y se conduce según normas totalmente diversas y propias, las cuales obran sobre él hasta en cosas tan elementales como la postura erguida (a diferencia del mamífero que desde su nacimiento manifiesta la postura natural de su especie). En aprender a vivir se nos va la vida:

el hombre se establece para sí un orden estructural de poder-hacer, el cual está en él como posibilidad que ha de ir sacando mediante adiestramiento o amaestramiento propio. El hombre es un ser abierto al mundo que no trae nada aprendido, sino que tiene que desarrollar un proceso de aprendizaje durante toda su vida ${ }^{21}$.

Gracias a la subjetividad corporal propia y a la influencia cultural, el ritmo de desarro-

19 Landmann, Antropología..., ob. cit., pp. 267-268.

20 Cfr. A. Portmann, Zoologie und das neue Bild des Menschen, citado en G. Haeffner, Antropología filosófica, traducción de C. Gancho, Barcelona, Herder, 1986, pp. 20-26.

21 Gehlen, El hombre..., ob. cit., p. 41. 
llo humano se inscribe en tiempos diferentes. El hombre crece hasta los veinte años, mientras que la ballena a los dos años de edad ya ha alcanzado el tamaño completo de veinte metros ${ }^{22}$. La juventud del hombre es más larga porque el proceso de comprensión y asimilación cultural es más dispendioso: "la apropiación de cultura es un proceso tan complejo que no sólo debe empezar pronto, sino que además necesita un período extraordinariamente largo" ${ }^{23}$.

La apropiación de cultura desempeña un papel imprescindible dentro del desarrollo humano, pero el hombre además de asimilar cultura, debe perfeccionar la autonomía de su corporeidad subjetiva. Esto nos brinda la oportunidad de sortear nuevas situaciones, esto es, de hacer evolucionar la cultura. Así, nos convertimos en hacedores y recreadores de nuestra propia cultura.

Veamos cómo el cuerpo propio, en tanto cuerpo subjetivo, nos muestra al hombre como un ser abierto al mundo, y al mundo como un ser cultivado y cultivable.

\section{La especialización cultural del cuerpo humano}

Los sentidos animales sólo son relevantes a una determinada zona del mundo. Ellos reaccionan únicamente ante unos estímulos y son completamente insensibles a otros:

para el animal el mundo se divide en lo comestible y lo no comestible, lo del mismo sexo y lo de sexo diferente, lo tranquilizador y lo angustioso. Aquello que no tiene ningún interés vital no existe para él. Los sentidos animales no son superfluos, sólo registran lo estrictamente necesario para sobrevivir ${ }^{24}$.

Los sentidos animales son filtros que dejan pasar a su través sólo las cosas significativas para su vida, pero son impermeables para

22 Cfr. Portmann, Zoologie..., ob. cit., pp. 20-26.

23 Landmann, Antropología..., ob. cit., p. 223.

24 Ibídem, p. 226. aquello que no está dentro de su campo de necesidades incondicionales. El animal no lleva a cabo ninguna actividad por sí mismo, la especie lo hace por él. Por ejemplo, la hembra de la garrapata sólo tiene tres sentidos -luz, olfato y temperatura-; con la ayuda del sentido de la luz encuentra el camino en una rama; los sentidos del olfato y la temperatura le dicen cuando pasa bajo la rama un animal de sangre caliente sobre el cual se tiene que dejar caer y cuya sangre tiene que beber. Así, el riquísimo mundo de la garrapata se ahoga y se transforma en un pobre hábitat que consta esencialmente de tres características. La lagartija, sensible al más leve de los ruidos, no reacciona si se dispara un arma de fuego junto a ella porque este tipo de percepción está más allá de su especialización sensorial; ningún animal que ponga en peligro su vida desarrolla semejante ruido ${ }^{25}$.

El animal percibe el hábitat como un todo organizado y es incapaz de separar una cosa del papel que desempeña con respecto al conjunto. No percibe éste como una reunión de partes, sino como una unidad compleja. El hábitat es comprendido dentro de un estricto sistema de relaciones, y cualquier cosa que esté por fuera de dicho sistema no existe para el animal. Si una mosca se arroja sobre una araña, ella no sabe qué hacer, no se la come porque sólo conoce las moscas que caen cautivas dentro de su red. La araña no reconoce la idoneidad de la mosca fuera de su sistema especializado ${ }^{26}$.

Los órganos humanos de conocimiento sensorial, al no estar especializados, no limitan al hombre tan sólo a una porción del mundo (hábitat), sino que nos abren hacia un mundo infinitamente posible, nos muestran el mundo como un campo ilimitado de admiración, en el que debemos orientarnos y del cual debemos apropiarnos:

nos orientamos en el mundo de los sentidos mediante ciertos símbolos ópticos, táctiles, acústicos, olfativos. Esto nos ahorra entregarnos a toda la plenitud posible de las cosas. Con la ayuda de

25 Cfr. ibídem, p. 228.

26 Cfr. ibídem. 
esos símbolos realizamos y dosificamos nuestros movimientos atendiendo a su finalidad, antes del éxito o fracaso ${ }^{27}$.

En consecuencia, una vez más, decimos que el hombre no representa un avance gradual sobre el animal: él NO es un animal mejor dotado para el conocimiento, sino un ser cuyo conocimiento presupone de antemano una corporeidad cualitativamente distinta.

El hombre, además de percibir lo necesario para su vida, también percibe aquello que tal vez utilizará más tarde o quizás nunca ${ }^{28}$. Nuestro campo de percepción va más allá de lo básico vital y se inserta en lo propiamente cultural:

Al hombre, el hambre futura también le da hambre. Por eso, es vitalmente importante que sus carencias se organicen en un marco que trascienda el momento actual. Sería una situación insoportable que sus indigencias sólo fueran superadas para el ahora. El hombre es un ser pre-visor que está orientado a lo lejano y que vive también en el futuro y no sólo en el presente $^{29}$.

El espacio vital del hombre no es un hábitat sino un mundo infinitamente abierto. Sin embargo, nuestra condición humana nos dice que somos seres finitos; que nuestro cuerpo es limitado y frágil; que frente a la infinitud de posibilidades que nos brinda la apertura al mundo no podemos responder de una vez por todas; que se hace necesario orientarnos intencionalmente para poder traducir la invasión de sensaciones que nos vienen del mundo. Nuestra existencia es paradójica porque a la vez se nos muestra como infinitud de posibilidades y como finitud de capacidades.

Es por esta razón que el mundo no puede ser agotado bajo una sola orientación, y que él varía según la intencionalidad de quien lo perciba. El roble para el leñador no significa lo mismo que para el científico; más aún, el trato que recibe un roble por parte de un leñador

27 Cfr. Gehlen, El hombre..., ob. cit., pp. 201-202.

28 Cfr. Zubiri, Siete ensayos..., ob. cit., pp. 27-30.

29 Gehlen, El hombre..., ob. cit., p. 59. europeo difiere del trato que le da un leñador indígena amazónico:

el ámbito cultural del hombre contiene las condiciones de su existencia física. La diferencia entre hombre cultural y hombre natural es equívoca. Ninguna población humana vive en regiones incultas, todas tienen técnicas, armas, fuego, utensilios... También es equívoca la distinción entre cultura y civilización. Cultura es la totalidad de las condiciones de la naturaleza dominadas, transformadas y aprovechadas por el hombre mediante su trabajo y actividad ${ }^{30}$.

Gracias a que su ser está dejado a la propia industria, el hombre debe orientarse dentro de la multitud de sensaciones que le brinda el mundo. Este movimiento reduce el mundo total a sub-mundos, los cuales son construidos o aprehendidos por el hombre a partir de centros corporales concretos, esto es, los sentidos. Tal reducción, además de permitirnos fundar nuestro estilo de vida, nos deja al mundo apto para futuros descubrimientos. El ser del mundo es como un misterio accesible y encubierto que se deja conocer según la actitud humana.

La apertura sensorial produce en nosotros una multiplicidad infinita de sensaciones que debemos reducir, poner entre paréntesis. En virtud de esta posibilidad realizamos nuestras creaciones culturales. Es decir, la apertura al mundo, al no brindarnos ningún punto de referencia natural a partir del cual las cosas estén fijamente estructuradas, nos impulsa a canalizar las sensaciones a través de nuestros sentidos y sus extensiones. De esta manera nos descargamos y procesamos todo el material sensitivo que nos abruma, y poco a poco vamos

incorporando y espiritualizando el mundo: la apertura al mundo es fundamentalmente una carga. El hombre está sometido a una sobreabundancia de estímulos, una plétora de impresiones sin finalidad, que afluyen a él y que tiene que dominar de alguna manera para poder vivir humanamente ${ }^{31}$.

30 Ibídem, p. 43.

31 Ibídem, p. 40. 
El mundo de los sentidos, antes de cualquier representación conceptual, ya es simbólico. Debido a la condición ilimitada del mundo, el hombre selecciona tan sólo una parte y lo percibe de esta o aquella manera, obteniendo así la forma simbólica de lo percibido. La captación de la forma nos brinda la posibilidad de percibir la realidad tanto en conjunto como en cada uno de sus elementos por separado:

en un ser abierto al mundo abunda la posibilidad sensorial. Por eso, el orientarse hacia las cosas y aprehenderlas (super-visarlas) mediante acciones sensibles permite una percepción panorámica que, aunque no capta la cosa en su totalidad, da noticias tanto de su generalidad como de su particularidad. La percepción proporciona las situaciones generales, que a partir de la re-flexión podemos disolver en sus particularidades ${ }^{32}$.

El mundo se nos da como un nudo de relaciones que tenemos que reorganizar con miras a elaborarnos una ayuda, una experiencia que sea aprovechable. Él, en cierta medida, va configurando nuestras necesidades y comportamientos, y nos hace comprender los alcances del cuerpo propio. Un clima frío junto a un relieve empinado, hace que debamos construirnos unos abrigos especiales, y que nuestra postura ya no sea erecta sino semi-inclinada: "la carga directa e inmediata que produce la multiplicidad de sensaciones tiene que ser transformada en una oportunidad de existir" ${ }^{\prime 33}$.

Ésta es la base de la diversidad cultural. Cada cultura desarrolla un sentido y estilo de productividad propios, gracias a que son selectivas con respecto a su percepción del mundo. A partir del horizonte total, el hombre articula un paisaje corpo-espiritual distinto que con el tiempo se convierte en el filtro que deja pasar sólo lo significativo para el estilo de vida cultural propio. El puritano anglosajón, enemigo de los sentidos, permanece cerrado frente a cierta clase de estímulos; estímulos por los que el latino trata de elevarse a lo más alto y desde allí cultiva su sensibilidad.

32 Ibídem, p. 201.

33 Ibídem, p. 44.
Es también en este campo donde se inscriben la variedad de lenguajes -gestuales y verbales-, ya que el hombre organiza sus percepciones y crea una estructura de símbolos que amplíe el radio de acción de sus sentidos. De esta manera el hombre enriquece sus vivencias y se hace capaz de actuar desde el mundo de los otros. Los lenguajes se muestran al hombre como la herramienta más idónea para dominar la apertura al mundo y para construir infinitud de planes de acción propios y comunes ${ }^{34}$.

La vida cultural que vemos alrededor nuestro es el resultado de la actividad humana. Por tanto, es un campo simbólico que nos remite siempre hacia experiencias ajenas $y$, a la vez, nos hace posible la existencia y la utilización de las cosas. Por esta razón, desde niños nos damos a la tarea de aprender cultura, con el objetivo de poder desenvolvernos en el mundo. Tarea que consiste en labores $u$ ocupaciones comunicativas que nos llevan a prepararnos para la vida y que debemos realizar así no tengan un valor inmediatamente satisfactorio:

todos llevamos la impronta de las tradiciones culturales de las comunidades en las que nos hemos criado y en las que nos encontramos. Esta herencia dibuja también las líneas de nuestro futuro. Las posibilidades son nuestras en la medida en que mantengamos cierta continuidad con dicha herencia ${ }^{35}$.

No obstante, la cultura propia, que hace el papel de filtro de nuestras sensaciones y a la que nos entregamos desde niños, no constituye una camisa de fuerza. El hombre es el ser más social y paradójicamente es al mismo tiempo el ser más individual. Como sujetos-corpóreos también poseemos la capacidad de re-flexionar, re-crear y re-orientar nuestros estilos y maneras de comportamiento. Dentro de las posibilida-

34 Pero el hombre no tiene que entrar en cada momento a inquirir de nuevo los objetos y decidir sobre su propia conducta. Cada individuo reúne experiencias y en cada grupo se perpetúan tradicionalmente tales experiencias. Siempre hay a disposición un tesoro del saber. Las instituciones, los inventos, se conservan, convirtiéndose en posesión perdurable que acompaña a la humanidad. Junto a la facultad de crearlas también tenemos la de conservarlas y convertirlas en instituciones sólidas, en bienes tradicionales. Cfr. Landmann, Antropología..., ob. cit., p. 261.

35 Ibídem, p. 256. 
des del hombre también está la de contemplar el mundo cultural desde sí mismo.

La vida que experimenta el mundo equidista entre estos dos modos de ser: uno impersonal constituido por la cultura dada, por medio del cual nos hacen hombres. Y otro personal por medio del cual estamos llamados a hacernos hombres, a hacernos sujetos-corpóreos autónomos ${ }^{36}$.

La apertura sensorial al mundo es el fundamento, la condición y la posibilidad de ambos momentos. La cultura dada es la respuesta creadora que algunos sujetos-corpóreos dieron a los interrogantes planteados por el mundo, con la intención de clarificar lo confuso, de organizar desde sí mismos el infinito caudal de posibilidades que desbordaban su ser. El sujeto-corporal autónomo es el que se apropia de este legado y lo percibe no como algo ya acabado, sino como algo a hacer evolucionar desde su experiencia y desde sus propias respuestas creadoras. La apertura al mundo hace de nosotros seres creadores y libres: libres de toda guía de instinto y libres para autodeterminarnos productivamente ${ }^{37}$.

\section{Los sentidos: condición de posibilidad de la creación de cultura}

La apertura sensorial del cuerpo humano nos conduce necesariamente a orientarnos intencionalmente en el mundo ${ }^{38}$. En virtud de esta orientación podemos y debemos crear cultura. El hombre es el único ser que encuentra ante sí una tarea abierta, la cual debe abordar mediante una actitud original. Ésta está enraizada en lo más profundo de nuestro plan estructural, es el espíritu humano, a través del que organizamos y canalizamos el caudal de sensaciones que nos brinda el mundo: "el cuerpo no es una adición al espíritu, sino una estructura permanente de mi ser; es la condición permanente de

36 Cfr. Merleau-Ponty, Fenomenología..., ob. cit., p. 230-231.

37 Cfr. Landmann, Antropología..., ob. cit., p. 244.

38 Cfr. Merleau-Ponty, Fenomenología..., ob. cit., p. 229 posibilidad de mi conciencia como conciencia del mundo y como proyecto trascendente hacia mi futuro" ${ }^{\prime 39}$.

El hombre debe ser creador de cultura, pero no debe serlo de un modo determinado $a$ priori. El hecho de que él, en tanto sujeto particular, aspire a completar y perfeccionar su ser no le da derecho a postular su modo de percepción ni su modo de re-flexión como la única válida en el mundo. La apertura al mundo nos brinda la posibilidad de responder de múltiples maneras y, por ende, niega de plano cualquier respuesta dogmática o absolutista ${ }^{40}$.

El modo de la respuesta creadora depende de nuestra orientación en el mundo, y en este campo los sentidos desempeñan un papel fundamental; ya que ellos no son objetos transparentes que capten sensaciones puras independientemente del espíritu, sino la opción que tomamos a favor de una orientación determinada ${ }^{41}$; ya sea de este o aquel modo, o en esta o aquella parte del mundo. El conocimiento sensitivo ya entraña un poder simbólico y comunicativo en co-relación con los demás seres del mundo.

Por consiguiente, la percepción humana es un acto cultural. La estructura corporal no es que permita el uso del espíritu, sino que forma cualitativamente su uso en todos los tipos de cultura humana ${ }^{42}$. Esto significa que los sentidos son vías de construcción, asimilación y

39 J.-P. Sartre, El Ser y la Nada: ensayo de una ontología fenomenológica, traducción de J. Valmar, Barcelona, Altaya, 1993, p. 354.

40 La antropología cientificista cayó en este error. Limitó nuestro ser a sus rígidos esquemas y pasó por alto toda la riqueza que representa la corporeidad. Planteó el conocimiento sensible desde un punto de vista objetivo y puro. Así redujeron los sentidos a objetos espaciales y creyeron que definían de una vez todo lo concerniente a la percepción. No se percataron que la sensación pura es un puro invento cultural que presupone de antemano un modo de percepción específico: el de la racionalidad analítica. El investigador no puede ser objetivo en absoluto porque él, en tanto sujeto-corpóreo, en todo momento está percibiendo el mundo desde el ángulo de una orientación particular. La antropología cientificista redujo la apertura al mundo a las estrechas propiedades de "un" cuerpo que no existe, que no es el cuerpo propio. Este cuerpo, al no existir, ya no nos pone en contacto con el mundo, sino con un concepto. El problema es que los sentidos del cuerpo propio son contemporáneos al mundo y sólo desarrollan su pleno significado en el momento de experimentarlos. Cfr. MerleauPonty, Fenomenología..., ob. cit., p. 223.

41 Cfr. Ibídem, p. 232.

42 Cfr. Zubiri, Siete ensayos..., ob. cit., p. 28-29. 
transmisión de valores culturales ${ }^{43}$. El habla, la escritura, la música, el cine, la culinaria, la aromaterapia, la escultura y hasta la ciencia, la filosofía y la religión son creaciones culturales que están condicionadas por el modo o los modos de percibir el mundo ${ }^{44}$ :

cada sentido responde los interrogantes del mundo a su manera. Es decir, que puedo proyectarme enteramente en un sentido. Puedo fijar la mirada mediante una actitud analítica o una actitud estética. Fijar la mirada es separar la región observada del resto del horizonte ${ }^{45}$.

La apertura al mundo hace que debamos reducir la plétora de sensaciones tan sólo al paisaje que decidamos escoger. Por tanto, la percepción sensorial puede hacerse desde múltiples dimensiones, según el valor que concedamos a los sentidos (claro está sin comprometer la unidad integral del cuerpo humano). Las culturas se van configurando según el énfasis que coloquemos a uno $u$ otro sentido. No todas las culturas utilizan los ámbitos sensoriales en la misma medida ${ }^{46}$. Las sensaciones se revisten de valor simbólico según el contexto donde se ejecuten. No es casualidad que los griegos definan el Ser como permanente presencia (ousia), ni que el credo judío empiece con las palabras escucha Israel; tampoco es casualidad que en el occidente cristiano sobreabunden las imágenes y los íconos de Dios, ni que la cultura semita las censure a todas.

Los significados que se derivan de las diversas sensaciones poseen un valor cultural muy rico y riguroso: "la vista puede estar asociada a la razón o a la brujería; el gusto puede servir metáfora para el refinamiento estético o para la experiencia sexual; un olor puede significar santidad, poder político o exclusión social” ${ }^{\prime 47}$.

43 Cfr. H. M. McLuhan, La comprensión de los medios de comunicación como extensiones del hombre, traducción de R. Palazón, México, Diana, 1969, pp. 13-18.

44 Cfr. C. Classen, "Fundamentos de una antropología de los sentidos". En línea: http://www.unesco.org/issj/rics153/classenpa.htlm (consultado 30-06-09), p. 1.

45 Merleau-Ponty, Fenomenología..., ob. cit., p. 240

46 Incluso, la enumeración de los sentidos varía según la cultura. Los hausas de Nigeria reconocen sólo dos sentidos: la percepción visual y la percepción no visual. Cfr. I. Ritchie, Fusión of the Faculties: a Study of the Language of the Senses. Citado en: Classen, "Fundamentos...", ob. cit., p. 2.

47 Classen, "Fundamentos...", ob. cit., p. 2.
Los significados sensoriales van configurando una especie de filtro perceptivo cultural que deja pasar a su través sólo aquello que es valioso para el estilo de vida propio. El residuo de esta operación se va constituyendo con el tiempo en el paradigma sensorial de tal o cual cultura. Los miembros que la componen, partiendo de esta base, pueden llegar a traducir esta experiencia en conceptos o en re-percepciones (re-presentaciones, cosmovisiones) de mundo. Es decir, el paradigma sensorial propio de cada cultura se nos muestra como el modelo básico que primero tenemos que aprender para luego, después de un largo proceso de apropiación y madurez, criticarlo, resistirlo o enriquecerlo.

Por tanto, la percepción humana no es algo dado por la naturaleza, sino un proceso de aprendizaje cultural. Los sentidos se educan y sus expresiones se aprenden:

los códigos sociales determinan, en cierta medida, la conducta sensorial de las personas en cualquier época y señalan el significado de las distintas experiencias sensoriales. Mirar fijamente a alguien puede significar grosería, halago o dominación; la mirada baja puede ser indicio de modestia, miedo, humildad o falta de atención. Los significados sensoriales varían según las circunstancias y según la cultura ${ }^{48}$.

La percepción sensorial no es un mero aspecto o propiedad de la experiencia corporal, sino su base misma; es el fundamento de todas las experiencias corporales. Experimentamos nuestro ser, el ser del mundo y el ser de los demás siendo sentidos ${ }^{49}$. El modelo sensorial adoptado por una cultura revela sus aspiraciones, preocupaciones, divisiones, jerarquías e interrelaciones. Los sentidos enmarcan la experiencia perceptiva según orientaciones personales y/o culturales ${ }^{50}$.

Según el modelo sensorial adoptado podemos decir que existen culturas visuales, orales, táctiles, olfativas, gustativas. La cultura occidental, a

48 Ibídem, p. 3.

49 Cfr. Merleau-Ponty, Fenomenología..., ob. cit., pp. 232-236.

50 Cfr. Ibídem. 
lo largo de la historia, ha colocado su énfasis perceptivo en el sentido de la vista porque siempre ha considerado que este sentido es el que está más estrechamente relacionado con la racionalidad $^{51}$. Veamos algunas de las consecuencias, tanto positivas como negativas, que trae consigo la adopción de este paradigma sensorial.

\section{Perspectivas: la cultura occidental: una cultura visual}

La primacía del sentido de la vista se observa ya en la mitología clásica. Edipo, después de ver la crudeza de su realidad, opta por sacarse los ojos. De esta manera se cegó no sólo al mundo de las cosas, sino también a su proyecto de vida. Este acto significó para Edipo reducir la existencia a su mínima expresión.

Este legado cultural pasó a la filosofía. Los pensadores clásicos consideraban el sentido de la vista como el sentido por excelencia, pues él nos revela la presencia de las $\operatorname{cosas}^{52}$.

Para Platón, la razón constituye "los ojos del alma". Idein, de donde viene la palabra idea, significa "ver no sensible". Idea significa "lo visto por el alma". Y así como el ver sensible necesita de la luz natural, el ver racional necesita de la luz del Ser. El mundo de las ideas es visual, es un mundo de figuras contempladas ${ }^{53}$.

Aristóteles también se rige por la hegemonía del sentido de la vista. Esto le permite desarrollar una filosofía inspirada en imágenes y objetivaciones del mundo. Él, una vez construido su esquema conceptual-visual, fue intercalando los demás sentidos. Así, comprendió al hombre desde la visión del ser, pero no al ser desde la visión del hombre ${ }^{54}$.

La cultura occidental acentuó más el sentido de la vista, en cuanto a su importancia

51 Cfr. Classen, “Fundamentos...", ob. cit., pp. 4-5.

52 Cfr. A. Synnott, "Puzzling over the Senses from Plato to Marx". Citado en: Classen, "Fundamentos...", ob. cit., p. 3.

53 Cfr. D. Cruz Vélez, Filosofía sin supuestos: de Husserl a Heidegger, Buenos Aires, Sudamericana, 1970, pp. 238-245.

54 Cfr. M. Buber, ¿Qué es el hombre?, traducción de E. Imaz, México, FCE, 1954, pp. 23-46. cultural, cuando la asoció al floreciente campo de la ciencia. En ese momento la mirada inquisitiva y penetrante del científico, ayudada por las extensiones ópticas como el microscopio y el telescopio, se convirtió en la metáfora de la adquisición de conocimiento ${ }^{55}$.

Las teorías de la evolución también favorecieron la elevación de este sentido al decretarlo el sentido de la civilización. Se supuso que los sentidos inferiores -olfato, gusto y tacto- perdían importancia conforme el hombre ascendía en la escala de la evolución: "existe una jerarquía sensorial de las razas humanas en la que el europeo (el hombre-ojo) ocupa el peldaño superior, seguido del asiático (el hombre-oído), el amerindio (el hombre-nariz), el australiano (el hombre-lengua) y el africano (el hombre-piel)" ${ }^{\prime \prime 56}$.

En los siglos XIX y XX, la función de la vista se amplió más con la invención de las tecnologías visuales como la fotografía, la televisión, el cine y la informática.

En consecuencia, la preferencia de Occidente por la visión ha permeado sus construcciones culturales en todos sus ámbitos: escritura, pensamiento, tecnología... Por eso, todos los paradigmas sensoriales de culturas extrañas fueron filtrados por la manera visual de percibir el mundo. La escritura, la lectura, los textos se han utilizado como esquemas fijos en el análisis cultural. Se creía que la cultura de un pueblo es un conjunto de textos que el investigador intenta leer por encima del hombro de sus propietarios. Muchos investigadores no fueron más allá de la descripción e interpretación visual de una cultura ajena. Por eso no se percataron de que existen objetos culturales que pierden toda su significación original si son abstraídos de su contexto dinámico y transformados en objetos estáticos, observables en las vitrinas de los museos o álbumes de fotografías. Hay un sinnúmero de obras de culturas ajenas que son hechas para

\footnotetext{
55 Cfr. Classen, "Fundamentos...", ob. cit., p. 3.

56 S. J. Gould, The Flamingo`s Smile: Reflections in Natural History. Citado en: Classen, "Fundamentos...", ob. cit., p. 6.
} 
ser aplicadas por el cuerpo y no simplemente para ser contempladas ${ }^{57}$.

Es evidente que el paradigma perceptivo occidental ha hecho avanzar la cultura humana en medidas extraordinarias. Pero, a la par, también ha sido objeto de discriminación cultural. Recordemos que los semitas, africanos, amerindios... fueron considerados por los occidentales como pre-humanos sin alma porque no compartían con ellos su manera de percibir el mundo. Las culturas estructuradas en otro sentido diferente al de la vista eran concebidas como primitivas o salvajes. Las distinciones raciales -blanco, negro, amarillo, zambo, mestizo- también se hicieron a partir de sensaciones visuales ${ }^{58}$.

La discriminación femenina también estuvo ligada a la percepción. Las mujeres fueron consideradas sólo como aptas para desarrollar sentidos inferiores, y por eso estaban destinadas a ambientes como la cocina, la cama o el cuarto de los niños; mientras que las labores superiores como la erudición, la aventura y el gobierno debían ser ejecutadas por el género masculino.

El énfasis visual hace que la explicitaciones o re-presentaciones de la cultura giren en torno a conceptos ópticos: contemplar, imagen, perspectiva, punto de vista, perfil, horizonte, cosmovisión, ideas, ideas claras, reflejo, evidencia, intuición, objeto, sujeto, texto, contexto, etc. También hace que los conceptos derivados de otras experiencias sensoriales vayan siendo sustituidos por conceptos ópticos: armonía de mundo por visión de mundo; olor a santidad por aura. Al estructurar esquemas puramente visuales para comprender otras culturas, también se puede pasar por alto que existen cultu-

57 Cfr. Classen, "Fundamentos...", ob. cit., pp. 4-5.

58 El estudio de los sentidos no es la prueba de una fase de la evolución, sino una de las claves esenciales sobre la manera como una sociedad crea y plasma un mundo con sentido. Una cultura extraña no puede ser estudiada según el modelo de la cultura propia. Esto significa que se deben descifrar los valores codificados en cada uno de los sentidos. Así, descubriremos un profundo simbolismo sensorial ignorado para poner de manifiesto la jerarquía de valores sensoriales que entraña cada cultura. Cfr. ibídem. ras que explicitan su modo de percibir el mundo a partir de complejos vocabularios no visuales ${ }^{59}$.

Como vemos, la especialización del cuerpo humano es la que hace posible la constitución de la cultura en general y de la cultura occidental en particular. De ahí que la definición del hombre a partir de la animalidad resulte inadecuada. Si tenemos en cuenta el rasgo distintivo de lo propiamente humano, las personas deben ser consideradas como realidades sui generis.

\section{Bibliografía}

1. Buber, M., ¿Qué es el hombre?, traducción de E. Imaz, México, FCE, 1954.

2. Buber, M., Eclipse de Dios: estudios sobre las relaciones entre religión y filosofía, traducción de L. Fabricant ; introducción de R. M. Seltzer, México, FCE, 1970.

3. Chauchard, P., Compendio de biología humana: las bases orgánicas de la conducta y del pensamiento; traducción de M. Testa; revisión de M. Balaguer, Buenos Aires, Universitaria, 1961.

4. Classen, C., "Fundamentos de una antropología de los sentidos". En línea: http:// www.unesco.org/issj/rics153/classenpa. htlm, (consultado 30-06-09).

5. Cruz Vélez, D., Filosofía sin supuestos: de Husserl a Heidegger, Buenos Aires, Sudamericana, 1970.

6. Dondeyne, A., Fe cristiana y pensamiento contemporáneo, traducción de J. Martín Velasco, Madrid, Cristiandad, 1963.

7. Gehlen, A., El hombre: su naturaleza y su lugar en el mundo, traducción de C. Vevia, Salamanca, Sígueme, 1987.

8. Haeffner, G., Antropología filosófica, traducción de C. Gancho, Barcelona, Herder, 1986.

59 Cfr. ibídem, p. 7. 
La corporeidad como apertura del hombre al mundo

9. Landmann, M., Antropología filosófica: autointerpretación del hombre en la historia y en el presente, traducción de C. Moreno, México, Uteha, 1961.

10. Luypen, W., Fenomenología existencial, traducción de P. Martín, Buenos Aires, Carlos Lohlé, 1967.

11. Merleau-Ponty, M., Fenomenología de la percepción, traducción de J. Cabanes, Barcelona, Península, 1975.
12. McLuhan, H. M., La comprensión de los medios de comunicación como extensiones del hombre, traducción de R. Palazón, México, Diana, 1969.

13. artre, J.-P., El Ser y la Nada: ensayo de una ontología fenomenológica, traducción de J. Valmar, Barcelona, Altaya, 1993.

14. Zubiri, X., Siete ensayos de antropología filosófica, G. Martínez (ed.), Bogotá, USTA, 1982. 
